\title{
DEGRADAÇÃO RUMINAL DA MATÉRIA SECA E PROTEÍNA BRUTA, DE ALIMENTOS CONCENTRADOS UTILIZADOS COMO SUPLEMENTOS PARA NOVILHOS
}

\author{
Ruminally degradation of the dry matter and crude protein, \\ of concentrade feeds used as supplementation in diet for young bulls \\ Rafael Henrique de Tonissi e Buschinelli de Goes ${ }^{1}$, Antonio Bento Mancio ${ }^{2}$, \\ Sebastião de Campos Valadares Filho ${ }^{3}$, Rogério de Paula Lana ${ }^{3}$
}

\begin{abstract}
RESUMO
Com o objetivo de avaliar a degradabilidade ruminal da matéria seca (MS) e da proteína bruta (PB) de diferentes alimentos concentrados utilizados na alimentação de bovinos, pela técnica in situ, foram utilizados três novilhos Nelores, inteiros, com 24 meses e peso aproximado de $350 \mathrm{Kg}$, fistulados no rúmen. As amostras referentes aos alimentos foram pesadas e colocadas no interior de sacos de náilon $(6,5 \mathrm{x} 4,0 \mathrm{~cm}$ de área livre), com porosidade conhecida de 50 micras, na quantidade de 1,0 grama de MS; esses foram incubados em ordem decrescente no rúmen nos tempos de 48, 36, 24, 12, 6, 3 e 0 horas. Foram avaliados seis alimentos: glúten de milho, polpa cítrica, farelo de soja, farelo de trigo, milho moído e o farelo de amendoim. Os dados foram ajustados por regressão não-linear, segundo o modelo $\mathrm{p}=\mathrm{a}+\mathrm{b}(1$-e-ct). As degradabilidades efetivas (DE) da matéria seca dos alimentos foram, respectivamente, de 29,$3 ; 76,6 ; 71,3 ; 60,5 ; 59,6 ;$ e 60,8 , para a taxa de passagem de $5 \% / \mathrm{h}$, e da proteína bruta foram de 8,$5 ; 56,1$; 57,$4 ; 67,9 ; 30,1 ;$ e 85,2, para a mesma taxa de passagem, respectivamente. A polpa cítrica apresentou alto valor para a degradabilidade efetiva de MS (76,6\%); o milho, uma lenta degradação ruminal da PB, com uma taxa de degradação para a fração "b" de 2,9\%; o glúten de milho apresentou uma fração "a" de 11,9\% para a MS, sendo uma fonte de proteína de alto escape ruminal, apresentou DE de 8,5\%; o farelo de amendoim apresentou valor, para a fração "b", de 67,3\%, o valor nutritivo desse alimento é semelhante ao farelo de soja, mas teve a maior DE de PB superior $48 \%$ ao farelo de soja. O glúten de milho apresentou baixa degradação ruminal, enquanto a polpa cítrica e o milho tiveram uma lenta degradação ruminal, principalmente quando comparados ao farelo de amendoim.
\end{abstract}

Termos para indexação: Alimentos concentrados, degradação ruminal, sacos de náilon, técnica “in situ”.

\section{ABSTRACT}

With the objective of evaluating the ruminal degradation of the dry matter and the crude protein of different concentrated feed used when feeding bovine, through the in situ technique, we used three young Nelore steers, rumen fistulated, with 24 months old, and weighting approximately $350 \mathrm{~kg}$. The feed samples were weighted and put inside of nylon bags $(6,5 \times 4,0 \mathrm{~cm}$ of free area) with 50 micras porosity in the quantity of $1,0 \mathrm{~g}$ of dry matter, and they were put in decreasing order in the rumen with intervals of $48,36,24$, 12, 6, 3 and 0 hours. Six feeds were analysed: corn gluten, citrus pulp, soybean meal, wheat meal, ground corn and peanut meal. The data were adjusted by non linear regression, according to the model $\mathrm{p}=\mathrm{a}+\mathrm{b}\left(1-\mathrm{e}^{\mathrm{ct}}\right)$. The effective degradability of the dry matter were, in order, 29, 3, 76, 6, 71, 3, 60, 4, 59, 6 and 60,8 , to the passage ratio of $5 \%$ an hour, and of the crude protein, 8,5; 56,1; 57,4; 67,9;30,1; and 85,2 fot the same passage ratio. The citrus pulp presented high value for the effective degradability of DM (76,6\%), the corn a slow degradation ruminal of $\mathrm{PB}$, with the value of the degradation ratio for the fraction " $\mathrm{b}$ " of 2,9\%, the corn gluten presented a fraction "a", of $11,9 \%$ for to DM; where a source of protein of high ruminal escape, it presented ED of 8,5\%; the peanut meal presented value, for the fraction "b", of $67,3 \%$, the nutritional value of this food is similar to the soy meal, but had the largest ED of CP $48 \%$ highest than the soy meal. The corn gluten presented low ruminal degradation, while the citrus pulp and the corn had slow ruminal degradation, specially when compared to the peanut meal.

Index terms: Concentraded feeds, ruminal degradation, nylon bags, "in situ" technique.

(Recebido para publicação em 4 de dezembro de 2002 e aprovado em 5 de maio de 2003)

\section{INTRODUÇÃO}

Conhecer a degradabilidade dos alimentos é essencial para formular dietas a serem fornecidas aos animais, nos cálculos de requerimentos protéicos, e atender às necessidades dos microrganismos ruminais que, por sua vez, são capazes de transformar compostos nitrogenados não-protéicos em proteína microbiana, proporcionando produção mais eficiente (Valadares Filho, 1994; Aroeira et al., 1996).

\footnotetext{
1. Doctor Scientie, Departamento de Zootecnia, UFV, 36571-000 - Viçosa, MG, rhtbg@uol.com.br/rgoes@umunet.com.br

2. Professor Adjunto do Departamento de Zootecnia/UFV. amancio@ufv.br

3. Professores do Departamento de Zootecnia/UFV, pesquisadores do CNPq.
} 
A técnica in situ provavelmente oferece a estimativa mais exata da degradação de proteína no rúmen do que as determinadas em laboratórios (Aufrére et al., 1991), permitindo melhor contato do alimento com o meio ruminal, não existindo a mastigação e a passagem, constituindo-se em um meio mais rápido para simular o ambiente no interior do rúmen perante um regime alimentar (temperatura, $\mathrm{pH}$, substrato, tampão e enzimas) (Nocek, 1988). As enzimas utilizadas pelas técnicas in vitro em contato com o líquido de rúmen não representam o ambiente ruminal e seus microrganismos (VAN SOEST, 1994).

A técnica in situ, apesar de sofrer várias críticas, como restrição ao acesso microbiano à proteína (Meyer e Mackie, 1986), contaminação microbiana dos sacos (Nocek e Grant, 1987) e perda de nitrogênio que não foi degradado, ainda é amplamente utilizada para a identificação das degradabilidades (Broderick, 1995). No Brasil, estudos são realizados com a utilização dessa técnica para avaliar forragens, resíduos agrícolas e produtos industriais, na alimentação de bovinos.

Neste trabalho, objetivou-se avaliar a degradabilidade efetiva, pela técnica in situ, de seis alimentos concentrados utilizados como suplementos em dietas para novilhos em pastejo.

\section{MATERIAL E MÉTODOS}

O experimento foi realizado nas dependências do Laboratório Animal do Departamento de Zootecnia da Universidade Federa de Viçosa (UFV), onde foram utilizados três novilhos Nelores inteiros, fistulados no rúmen, mantidos no pasto, recebendo apenas suplementação mineral, com idade aproximada de 24 meses e peso médio de $350 \mathrm{~kg}$.

Para as avaliações, utilizou-se a técnica in situ descrita por Mehrez e Orskov (1977), para se determinar a degradabilidade potencial e efetiva da matéria seca (MS) e da proteína bruta (PB) de seis alimentos concentrados utilizados na alimentação animal: farelo de soja, farelo de amendoim, polpa cítrica, glúten de milho, farelo de trigo e grão de milho moído, cuja composição bromatológica é mostrada na Tabela 1. As amostras foram preparadas segundo as recomendações propostas por Nocek (1988), em que os alimentos foram moídos com peneira de $2 \mathrm{~mm}$ de malha, pesados, para que se respeitasse a quantidade de $1,0 \mathrm{~g}$ de $\mathrm{MS}$, e colocados no interior de sacos de náilon com porosidade conhecida de 50 micras, com dimensões 6,5 x 4,0 cm de área livre; com isso, proporcionou-se uma relação de $20 \mathrm{mg} / \mathrm{cm}^{2}$ (Nocek, 1988). Os sacos foram incubados em ordem decrescente de 48, 36, 24, 12, 6, 3 e 0 horas, em triplicatas por animal e por tempo de incubação, sempre na parte da manhã (Orskov, 1988; Nocek, 1988).

TABELA 1 - Teores médios de matéria seca (MS) e proteína bruta $(\mathrm{PB})$ dos alimentos incubados.

\begin{tabular}{llc}
\hline \multicolumn{1}{c}{ Alimentos } & MS & PB \\
\hline Glúten de milho & 89,8 & 62,2 \\
Farelo de soja & 85,5 & 47,9 \\
Farelo de trigo & 83,1 & 17,9 \\
Farelo de amendoim & 91,9 & 58,4 \\
Polpa cítrica & 85,5 & 7,1 \\
Milho & 86,3 & 8,2 \\
\hline
\end{tabular}

${ }^{1}$ Dados obtidos no LNA da Universidade Federal de Viçosa.

As amostras dos alimentos utilizados e os resíduos remanescentes das incubações foram secos em estufa ventilada a $65^{\circ} \mathrm{C}$, por 48 horas, e analisadas, para se determinar os teores de matéria seca (MS) e de proteína bruta (PB).

Os dados sobre desaparecimento da matéria seca e proteína bruta foram calculados baseando-se na diferença entre o peso incubado e os resíduos após a incubação. Para a estimativa dos parâmetros de degradação, utilizou-se o programa estatístico SAEG (UFV, 2000), mediante ajustes por regressão nãolinear, segundo modelo proposto por Orskov e McDonald (1979): DP $=a+b\left(1-e^{-c t}\right)$, em que DP é a degradabilidade ruminal potencial dos alimentos; "a" é a fração solúvel; "b", a fração potencialmente degradável da fração insolúvel que seria degradada a uma taxa "c"; "c", que seria a taxa de degradação da fração "b"; e "t", o tempo de incubação em horas. A fração considerada não degradável seria calculada da seguinte forma: $(100-(a+b))$.

A degradabilidade ruminal efetiva (DE) do componente nutritivo analisado foi calculada segundo o modelo matemático proposto por Orskov e McDonald (1979): $\mathrm{DE}=\mathrm{a}+[(\mathrm{b} * \mathrm{c}) /(\mathrm{c}+\mathrm{K})]$, em que $\mathrm{K}$ é $\mathrm{a}$ taxa de passagem de sólidos pelo rúmen, definida aqui como sendo de 2,5 e $8,0 \% / \mathrm{h}$.

\section{RESULTADOS E DISCUSSÃO}

Os parâmetros "a", "b" e "c", a fração indegradável (I) e degradabilidade efetiva (DE) da MS, para as taxas de passagem de 2, 5 e $8 \% / \mathrm{h}$, são mostrados na Tabela 2 . A degradabilidade potencial dos alimentos (DP) para os diferentes tempos de incubação estão na Tabela 3. 
TABELA 2 - Frações solúvel (a), potencialmente degradável (b), taxa de degradação (c), coeficiente de determinação $\left(\mathrm{r}^{2}\right)$, fração indegradável (I) e degradabilidade potencial (DP) e efetiva (DE) da MS para as taxas de passagem de 2,5 e $8 \% / \mathrm{h}$.

\begin{tabular}{lcccccccc}
\hline \multicolumn{1}{c}{ Alimento } & \multicolumn{1}{c}{$\mathbf{c}$} & \multicolumn{3}{c}{ DE } \\
\cline { 2 - 9 } & $\mathbf{a}(\boldsymbol{\%})$ & $\mathbf{b}(\boldsymbol{\%})$ & $\mathbf{c}$ & $\mathbf{R}^{\mathbf{2}}$ & $\mathbf{I}(\boldsymbol{\%})$ & $\mathbf{2 \% / h}$ & $\mathbf{5 \% / h}$ & $\mathbf{8 \% / h}$ \\
\hline Glúten de milho & 11,9 & 60,3 & 0,021 & 0,99 & 27,97 & 42,3 & 29,3 & 24,1 \\
Farelo de soja & 34,5 & 64,7 & 0,066 & 0,97 & 0,8 & 84,1 & 71,3 & 63,7 \\
Farelo de trigo & 31,6 & 38,9 & 0,144 & 0,95 & 29,5 & 65,8 & 60,5 & 56,6 \\
Farelo Amendoim & 20,0 & 67,3 & 0,077 & 0,97 & 12,7 & 73,4 & 60,8 & 52,9 \\
Polpa cítrica & 37,1 & 58,3 & 0,105 & 0,96 & 4,6 & 86,1 & 76,6 & 70,2 \\
Milho & 23,2 & 75,5 & 0,047 & 0,99 & 1,3 & 76,0 & 59,6 & 51,0 \\
\hline
\end{tabular}

TABELA 3 - Degradabilidade Potencial da Matéria Seca dos alimentos em novilhos nos diferentes tempos de incubação.

\begin{tabular}{lccccccc}
\hline \multirow{2}{*}{ Alimento } & \multicolumn{7}{c}{ Tempo (horas) } \\
\cline { 2 - 8 } & $\mathbf{0}$ & $\mathbf{3}$ & $\mathbf{6}$ & $\mathbf{1 2}$ & $\mathbf{2 4}$ & $\mathbf{3 6}$ & $\mathbf{4 8}$ \\
\hline Glúten de milho & 11,9 & 15,57 & 19,02 & 25,29 & 35,7 & 43,79 & 50,08 \\
Farelo de soja & 34,5 & 46,12 & 55,66 & 69,89 & 85,93 & 93,19 & 96,48 \\
Farelo de trigo & 31,60 & 42,25 & 54,10 & 63,59 & 69,27 & 70,28 & 70,46 \\
Farelo Amendoim & 20,00 & 33,80 & 44,90 & 60,59 & 76,70 & 83,09 & 85,63 \\
Polpa cítrica & 37,10 & 52,85 & 64,35 & 78,86 & 90,71 & 94,07 & 95,02 \\
Milho & 23,20 & 33,13 & 41,75 & 55,75 & 74,26 & 84,80 & 90,79 \\
\hline
\end{tabular}

A fração solúvel (a) corresponde à parte solúvel do alimento, mais as partículas eliminadas através da malha dos sacos, quando esses são imersos no líquido ruminal e, posteriormente, lavados em água corrente. $\mathrm{O}$ milho apresentou valor semelhante $(23,2 \%)$ ao encontrado por Pereira et al. (1997), que foi de 20,3\%, mas inferior ao encontrado por Martins et al. (1999), de $32,9 \%$. Entretanto, a fração potencialmente degradável $(75,5 \%)$ e a taxa de degradação da fração "b" $(4,7 \%)$ foram superiores aos valores encontrados por ambos os autores, 63,1 e $67,1 \%$ e 0,4 e $3,7 \%$, respectivamente. As degradabilidades da MS obtidas neste trabalho, para as taxas de passagem de 2, 5 e $8 \% / \mathrm{h}$, foram de 76,0; 59,6; e $51,0 \%$, superiores aos encontrados por Martins et al. (1999), cujos valores são 43,2; 37,6; e 36,0\%. Para a taxa de $5 \% / \mathrm{h}$, o valor obtido está próximo ao valor médio apresentado pelo NRC (1996), de 55\%, mas inferior ao encontrado por Deschamps (1994), de 66,6\%. O valor encontrado por Pereira et al. (1997), sem o lag time, foi de $55,4 \%$, para taxa de passagem de $3,41 \% / \mathrm{h}$.
A polpa cítrica, que apresentou alto valor para a degradabilidade efetiva de MS (76,6\%) para taxa de passagem de $5 \% / \mathrm{h}$, apresentou valor superior ao encontrado por Martins et al. (1999), de 67,5\%, e ao NRC (1996), que preconiza degradação ruminal para a polpa cítrica de $70 \%$. A fração solúvel obtida foi de $37,1 \%$ e a taxa de degradação da fração "b", 10,5\%. Diferenças nos conteúdos dos nutrientes da polpa seca são atribuídas ao processo de desidratação, à fonte e à variedade da fruta e ao tipo de operação para a obtenção do resíduo (AMMERMAN e HENRI, 1993, citados por MARTINS et al., 1999). Os valores obtidos por Dewhurst et al. (1995) para a fração solúvel e a taxa de degradação da fração "b" foram semelhantes aos encontrados neste trabalho, que foram de $33,5 \%$ e $7,6 \% / \mathrm{h}$. Silva et al. (1997) mostraram alta degradabilidade da matéria seca para a polpa cítrica no rúmen, sugerindo alto valor energético para bovinos. Com isso, pode ser usado como alimento energético, porém, a única limitação é o fator econômico. 
O glúten de milho apresentou alto valor para a fração "a", 11,9\%, sendo superior ao apresentado por Teixeira et al. (1996), 5,9\%, mas a taxa de degradação da fração "b" de 2,1\% foi inferior à obtida pelo mesmo autor, $3,9 \%$, com uma fração não degradável de $45,8 \%$, superior à encontrada neste trabalho de $27,97 \%$. Todavia, a degradabilidade efetiva para a taxa de passagem de $5 \% / \mathrm{h}$ foi semelhante para os dois trabalhos, 29,3 e $27,1 \%$, respectivamente, possivelmente devido à sua baixa solubilidade, sendo inferior à degradabilidade do milho em grão moído, que foi de 59,6\%. A maior degradabilidade do milho possivelmente foi atribuída à presença do amido, que é susceptível à ação das amilases.

A fração "a" do farelo de trigo obtida foi de $31,6 \%$, sendo superior à encontrada por Deschamps (1994), que foi de 20,2\%, mas inferior à obtida por Martins et al. (1999), de 61,5\%. A taxa de degradação da fração "b" de $14,4 \%$ foi ligeiramente superior à encontrada por Aroeira et al. (1996), de 9,8\%/h. A degradabilidade efetiva da MS para esse alimento $(60,5 \%)$ foi semelhante aos valores encontrados por Deschamps (1994) e Martins et al. (1999), de 60,2 e $61,2 \%$, respectivamente, e Valadares Filho (1994), de 62\%, em uma coletânea de dados, para a taxa de passagem de 5\%/h. Van Soest (1994) mostrou o farelo de trigo com degradabilidade de $70 \%$, sendo o teor de fibra do alimento responsável por parte dessa degradação, principalmente da digestão da parede celular. Alimentos com alto teor de fibra apresentam baixa degradabilidade efetiva, com baixas frações solúveis (DEWHURST et al., 1995).

Os valores dos parâmetros "a", "b" e "c" para a MS do farelo de soja obtidos neste trabalho foram semelhantes aos encontrados por Teixeira et al. (1996), de $34,5 \%, 65,0 \%$ e $6,3 \% / \mathrm{h}$, e por Batajoo e Shaver (1998), de $35,4 \%, 63,6 \%$ e 5,8\%/h. Rossi Júnior et al. (1997) obtiveram valores superiores, de $35,3 \%, 61,9 \%$ e $7,23 \% / \mathrm{h}$, respectivamente. A taxa de degradação "c" foi superior àquela encontrada por Ha e Kennely (1984), de $5 \% / \mathrm{h}$. A DE da MS para a taxa de passagem de $2 \% / \mathrm{h}$ $(84,1 \%)$ foi superior ao valor médio encontrado por Valadares Filho (1994), de 82,4\%, mas inferior à de Martins et al. (1999), de 85,6\%. Vilela et al. (1994) obtiveram valores de DE, com taxa de passagem de $5 \% / \mathrm{h}$, inferiores aos encontrados neste trabalho, de $64,7 \%$, para vacas mestiças gestantes.

Moron et al. (2001) destacam maiores valores de degradabilidade de alimentos com frações altamente fermentescíveis, em que ocorreram absorção dos produtos finais de fermentação e manutenção do $\mathrm{pH}$ em limite aceitáveis, com o farelo de soja apresentando uma fração solúvel de 46,2\% e uma degradadilidade efetiva de $68,3 \%$, valores esses um pouco inferiores ao encontrado neste experimento, que foi de $71,3 \%$.

$\mathrm{O}$ farelo de amendoim apresentou um dos maiores valores entre os alimentos, para a fração "b", de
$67,3 \%$ (inferior apenas ao do milho de 75,5\%), com taxa de degradação de $7,7 \%$, caracterizando esse alimento como potencialmente degradável no rúmen. A degradabilidade efetiva da MS foi de $60,8 \%$ para taxa de passagem de $5 \% / \mathrm{h}$. O valor nutritivo desse alimento é semelhante ao farelo de soja, porém, a DE do farelo de soja foi $17 \%$ maior que a do farelo de amendoim, com uma menor taxa de degradação da fração "b" $(6,6 \% / \mathrm{h})$.

Os parâmetros "a", "b" e "c" e a fração indegradável dos alimentos incubados e sua degradabilidades efetivas (DE) da proteína bruta (PB), para as taxas de passagem de 2,5 e $8 \% / \mathrm{h}$, estão na Tabela 4 . $\mathrm{Na}$ tabela 5 são apresentadas as degradabilidades potenciais (DP) da PB dos alimentos nos diferentes tempos de incubação.

A fração "a" da PB do milho apresentou baixo valor $(3,4 \%)$ e foi inferior ao valor encontrado por Pereira et al. (1997), de 29,1\%, e Martins et al. (1999), de $38 \%$. A DE da PB foi de $30,1 \%$, valor inferior aos encontrados pelos autores acima, 62,5 e 40,2\%, respectivamente, e ao NRC (1996), 45\%. Porém, o NRC (1984) informa que a degradação do milho em dietas que apresentam mais de 35\% de forragens está associada ao tamanho da moagem. Wadhwa et al. (1998) relataram a relação inversamente proporcional entre a solubilidade $\mathrm{e}$ o tamanho da partícula. Esse alimento apresentou lenta degradação ruminal, em que o valor da taxa de degradação de fração "b" foi de $2,9 \%$ e o da fração solúvel, de $3,4 \%$, com uma fração não degradável de $24,1 \%$. O NRC (1984) classificou a degradação protéica do milho como de médio escape ruminal.

A polpa cítrica apresentou DE da PB de $56,1 \%$, para taxa de passagem de $5 \% / \mathrm{h}$, porcentagem inferior ao valor encontrado por Martins et al. (1999), que foi de $62,1 \%$. O NRC (1996) preconiza degradação ruminal da PB de $70 \%$. Silva et al. (1997) encontraram valores semelhantes ao deste trabalho, de $56,6 \%$, com taxa de degradação da fração "b" de $3,7 \% / \mathrm{h}$.

O NRC (1984) e Alcade et al. (1994) consideraram o glúten de milho uma fonte de proteína de alto escape ruminal, acima de $60 \%$. Neste trabalho, esse alimento apresentou DE de 8,5\% para taxa de passagem de 5\%, inferior aos valores obtidos por Teixeira et al. (1996), Rodriguez et al. (1996), que foram de 34 e $24 \%$, respectivamente. Porém, a fração solúvel foi baixa $(0,2 \%)$ e a taxa de degradação da fração "b", de $0,5 \%$, valores inferiores aos apresentados pelo primeiro autor, que foi de $3,2 \%$. Isso leva a menores taxas de DE para altas taxas de passagem, proporcionando alto escape ruminal. Variações entre estudos podem ser decorrentes do tamanho das partículas e dos métodos de processamento (BATAJOO e SHAVER, 1998). Essa diferença pode ter ocorrido em razão do teor de PB do glúten de milho utilizado neste trabalho e em Teixeira et al. (1996), cujas porcentagens foram 54,8 e $61,6 \%$, respectivamente.

Ciênc. agrotec., Lavras, v. 28, n. 1, p. 167-173, jan./fev., 2004 
TABELA 4 - Frações solúvel (a), potencialmente degradável (b), taxa de degradação (c), coeficiente de determinação $\left(\mathrm{r}^{2}\right)$, fração indegradável (I) e degradabilidade potencial (DP) e efetiva (DE) da PB para as taxas de passagem de 2,5 e $8 \% / h$.

\begin{tabular}{lcccccccc}
\hline \multicolumn{1}{c}{ Alimento } & & & & & & \multicolumn{3}{c}{$\mathbf{D E}$} \\
\cline { 7 - 10 } & $\mathbf{a}(\boldsymbol{\%})$ & $\mathbf{b}(\boldsymbol{\%})$ & $\mathbf{c}$ & $\mathbf{R}^{\mathbf{2}}$ & $\mathbf{I}(\boldsymbol{\%})$ & $\mathbf{2 \% / h}$ & $\mathbf{5 \% / h}$ & $\mathbf{8 \% / h}$ \\
\hline Glúten de milho & 0,2 & 94,9 & 0,005 & 0,85 & 4,9 & 18,7 & 8,5 & 5,5 \\
Farelo de soja & 9,4 & 86,8 & 0,062 & 0,96 & 3,8 & 74,9 & 57,4 & 47,3 \\
Farelo de trigo & 25,9 & 55,2 & 0,159 & 0,95 & 18,9 & 74,9 & 67,9 & 62,7 \\
Farelo Amendoim & 20,9 & 75,0 & 0,300 & 0,94 & 4,1 & 91,2 & 85,2 & 80,1 \\
Polpa cítrica & 9,4 & 82,8 & 0,065 & 0,90 & 7,8 & 72,6 & 56,1 & 46,4 \\
Milho & 3,4 & 72,5 & 0,029 & 0,95 & 24,1 & 46,3 & 30,1 & 22,8 \\
\hline
\end{tabular}

TABELA 5 - Degradabilidade Potencial da Proteína Bruta dos alimentos em novilhos nos diferentes tempos de incubação.

\begin{tabular}{lccccccc}
\hline \multirow{2}{*}{\multicolumn{1}{c}{ Alimento }} & \multicolumn{7}{c}{ Tempo (horas) } \\
\cline { 2 - 8 } & $\mathbf{0}$ & $\mathbf{3}$ & $\mathbf{6}$ & $\mathbf{1 2}$ & $\mathbf{2 4}$ & $\mathbf{3 6}$ & $\mathbf{4 8}$ \\
\hline Glúten de milho & 0,2 & 1,61 & 3,00 & 5,72 & 10,93 & 15,83 & 20,45 \\
Farelo de soja & 9,4 & 24,13 & 36,36 & 54,95 & 76,60 & 86,89 & 91,78 \\
Farelo de trigo & 25,9 & 46,84 & 59,83 & 72,91 & 79,89 & 80,92 & 81,07 \\
Farelo Amendoim & 20,9 & 65,41 & 83,50 & 93,85 & 95,84 & 95,90 & 95,90 \\
Polpa cítrica & 9,4 & 24,07 & 36,14 & 54,25 & 74,81 & 84,22 & 88,54 \\
Milho & 3,4 & 9,44 & 14,98 & 24,71 & 39,75 & 50,38 & 37,88 \\
\hline
\end{tabular}

O farelo de trigo apresentou DE da PB de $67,9 \%$ para taxa de passagem de $5 \%$, sendo inferior ao valor médio encontrado por Valadares Filho (1995), de 75,5\%. Martins et al. (1999) e Aroeira et al. (1996) obtiveram valores superiores ao deste trabalho, ou seja, 86,5 e $84,7 \%$, respectivamente. O NRC (1996) idealiza uma degradabilidade ruminal para a $\mathrm{PB}$ desse alimento bem superior $(80 \%)$ à encontrada nesta pesquisa. Essa diferença pode ser decorrente dos valores da fração "a" (solúvel), que foi de 25,9\%, inferior à Martins et al. (1999), que foi de $55,8 \%$, porém, a taxa de degradação da fração "b" deste trabalho $(15,9 \%)$ foi semelhante ao valor de $15,5 \%$ encontrado por Martins et al. (1999). Isso pode ser explicado, em parte, pela grande variedade na composição do farelo, conseqüência da forma de obtenção do material da indústria.

Os farelos de soja e amendoim são classificados pelo NRC (1984) como de baixo escape e de alta degradabilidade ruminal (66 e 70\%, respectivamente) (NRC, 1996). A DE para o farelo de soja foi de $47,3 \%$, semelhante à obtida por Martins et al. (1999), de 51\%, para taxa de passagem de 8\%/h e de Valadares Filho (1995), de 55\%. Rossi Júnior et al. (1997) obtiveram DE de 80,05\%, quando a taxa de passagem foi de $2 \% / \mathrm{h}$, sem considerar o "lag time". Broderick (1995), utilizando o método in situ, obteve valores de 14\%, $86 \%$ e $6,7 \% /$ h para a fração "a", fração "b" e taxa de degradação da fração "b", respectivamente, valores semelhantes aos encontrados neste trabalho. Vilela et al. (1994), para taxa de passagem de $5 \% / \mathrm{h}$, obteve DE efetiva de $64,7 \%$.

O farelo de amendoim teve a maior DE de $\mathrm{PB}$ entre os alimentos incubados e foi $48 \%$ superior ao farelo de soja e maior que os valores citados pelo NRC (1996). A fração solúvel foi de $20,9 \%$, com taxa de degradação da fração "b" de $30 \%$. 
A manipulação dos sacos, a contaminação microbiana e a possível perda de material não-degradado pelos poros do tecido podem ter influenciado alguns resultados.

\section{CONCLUSÕES}

O glúten de milho apresentou baixa degradação ruminal, e a polpa cítrica e o milho, lenta degradação ruminal, principalmente quando comparados ao farelo de amendoim.

O farelo de amendoim apresentou valores superiores ao farelo de soja, podendo agir como um substituto para proteína degradada no rúmen.

\section{REFERÊNCIAS BIBLIOGRÁFICAS}

ALCADE, C. R.; GUIN, A.; TONANI, F. L. Avaliação da degradabilidade ruminal da glutenose $60 \mathrm{em}$ bovinos. In: REUNIÃO ANUAL DA SOCIEDADE BRASILEIRA DE ZOOTECNIA, 31., 1994, Maringá. Anais... Maringá: SBZ, 1994. p. 521.

AROEIRA, L. J. M.; LOPES, F. C. F.; DAYRELL, M. S. Degradabilidade de alguns alimentos no rúmen de vacas Holandês/Zebu. Revista da Sociedade Brasileira de Zootecnia, Viçosa, v. 25, n. 6, p. 1178-1186, nov./dez. 1996.

AUFRÉRE, J.; GRAVIOU, D.; DEMARQUILLY, C. Predicting in situ degradability of feed proteins in the rumen by two labiratory methods: solubility and enzymatic degradation. Animal Feed Science Technology, Amsterdam, v. 33, n. 1/2, p. 97-116, 1991.

BATAJOO, K. K.; SHAVER, R. D. In situ dry matter, crude protein, and starch degradabilities of selected grains and by-products feeds. Animal Feed Science Technology, Amsterdam, v. 71, p. 165-176, 1998.

BRODERICK, G. A. Methodology for the determining ruminal degradability of feed proteins. In: SIMPÓSIO INTERNACIONAL SOBRE EXIGÊNCIAS NUTRICIONAIS EM RUMINANTES, 1995, Viçosa. Anais... Viçosa: UFV, 1995. p. 139-176.

DESCHAMPS, F. C. Degradabilidade ruminal da matéria seca e da proteína bruta de alguns alimentos utilizáveis na alimentação de ruminantes. Revista da Sociedade Brasileira de Zootecnia, Viçosa, v. 23, n. 6, p. 898-908, 1994.

DEWHURST, R. J.; HEPPER, D.; WEBSTER, A. J. F. Comparison of in sacco and in vitro techniques foe estimating the rate and extent of rumen fermentation of a range of dietary ingredients. Animal Feed Science Technology, Amsterdam, v. 5, p. 211-229, 1995.

HA, J. K.; KENNELY, J. J. In situ dry matter and protein degradation of various protein sources in dairy cattle. Canadian Journal Animal Science, Ottawa, v. 64, n. 6, p. 443-452, 1984

MARTINS, A. S.; ZEOULA, L. M.; PRADO, I. N. Degradabilidade ruminal in situ da matéria seca e proteína bruta das silagens de milho e sorgo e de alguns alimentos concentrados. Revista da Sociedade Brasileira de Zootecnia, Viçosa, v. 28, n. 5, p. 11091117, 1999.

MEHREZ, A. Z.; ORSKOV, E. R. A study of the artificial fibre bag technique for determining the digestibility of feeds in the rumen. Journal Agricultural Science, Cambridge, v. 88, n. 3, p. 645-650, 1977.

MEYER, J. H. F.; MACKIE, R. I. Microbiological evaluation of the intraruminal in sacculus digestion technique. Applied Environment Microbiology, Washington, v. 51, p. 622-629, 1986.

MORON, I. R.; TEIXEIRA, J. C.; BUENO FILHO, J. S. S. Cinética de degradação ruminal da matéria seca de alimentos concentrados e volumosos através das técnicas in vitro e in situ. Ciência e Agrotecnologia, Lavras, v. 25, n. 5, p. 1185-1194, 2001.

NATIONAL RESEARCH COUNCIL. Nutrient requeriments of beef cattle. Washington: National Academy, 1984. $91 \mathrm{p}$.

NATIONAL RESEARCH COUNCIL. Nutrient requeriments of beef cattle. Washington: National Academy, 1996. 242 p.

NOCEK, J. E. In situ and others methods to estimate ruminal protein and energy digestibility. Journal Dairy Science, Champaign, v. 71, p. 2051-2069, 1988.

NOCEK, J. E.; GRANT, A. L. Characterization of in situ nitrogen and fifer digestion and bacterial nitrogen contamination of hay crop forages preserved at different dry matter percentagem. Journal Animal Science, Champaign, v. 64, p. 552-564, 1987.

ORSKOV, E. R. Nutrición proteica de los ruminantes. Zaragoza: Acribia, 1988. 178 p.

ORSKOV, E. R.; MCDONALD, I. The estimation of protein degradability in the rumen from incubation

Ciênc. agrotec., Lavras, v. 28, n. 1, p. 167-173, jan./fev., 2004 
measurements weighted according to rate of passage. Journal Agricultural Science, Cambridge, v. 92, n. 1, p. 499-508, 1979.

PEREIRA, J. R. A.; BOSE, M. L. V.; BOIN, C. Avaliação das sub-frações dos carboidratos e das proteínas, usando a metodologia do CNCPS e in situ com bovinos da raça Nelore: II. milho e farelo de algodão. Revista da Sociedade Brasileira de Zootecnia, Viçosa, v. 26, n. 4, p. 838-843, 1997.

RODRIGUEZ, N. M.; MOREIRA, J. F.; CHRISTO, P. C. Digestibildades "in situ" e intestinal de fontes protéicas, determinadas em novilhos. In: REUNIÃO

ANUAL DA SOCIEDADE BRASILEIRA DE ZOOTECNIA, 33., 1996, Fortaleza. Anais... Fortaleza: SBZ, 1996. p. 452-454.

ROSSI JÚNIOR, P.; SILVA, A. G.; WANDERLEY, R. C. Degradabilidade ruminal da matéria seca e da fração protéica da silagem de milho, do farelo de soja e do sorgo em grão, em bovinos da raça Nelore: comparação com os dados obtidos pelo CNCPS. Revista da Sociedade Brasileira de Zootecnia, Viçosa, v. 26, n. 3, p. 599-607, 1997.

SILVA, A. G.; WANDERLEY, R. C.; PEDROSO, A. F. Ruminal digestion kinetics of citrus pell. Animal Feed Science Technology, Amsterdam, v. 68, p. 247-257, 1997.

TEIXEIRA, J. C.; DAVID, F. M.; PEREZ, J. R. O. Cinética da digestão ruminal da matéria seca e da proteína bruta de diferentes suplementos protéicos, em vacas da raça Nelore. In: REUNIÃO ANUAL DA SOCIEDADE BRASILEIRA DE ZOOTECNIA, 33., 1996, Fortaleza. Anais... Fortaleza: SBZ, 1996. p. 91-93.
UNIVERSIDADE FEDERAL DE VIÇOSA. SAEG - Sistema de análises estatísticas e genéticas. Versão 8.0. Viçosa, 2000. 142 p. Manual do usuário.

VALADARES FILHO, S. C. Eficiência de síntese de proteína microbiana, degradação ruminal e digestibilidade intestinal da proteína bruta, em bovinos. In: SIMPÓSIO INTERNACIONAL SOBRE EXIGÊNCIAS NUTRICIONAIS DE RUMINANTES, 1995, Viçosa. Anais... Viçosa: UFV, 1995. p. 355-455.

VALADARES FILHO, S. C. Utilização da técnica "in situ" para a avaliação de alimentos. In: SIMPÓSIO INTERNACIONAL DE PRODUÇÃO DE RUMINANTES; REUNIÃO ANUAL DA SOCIEDADE BRASILEIRA DE ZOOTECNIA, 31., 1994, Maringá. Anais... Maringá: SBZ, 1994. p. 95-118.

VAN SOEST, P. J. Nutritional ecology of the ruminant. 2. ed. New York: Cornell University, 1994. $476 \mathrm{p}$.

VILELA, G. L.; VALADARES FILHO, S. C.; SILVA, J. F. C. da. Degradabilidade "in situ" da matéria seca e da proteína bruta e proteína efetivamente degradada no rúmen, de vários alimentos. Revista da Sociedade Brasileira de Zootecnia, Viçosa, v. 23, n. 3, p. 342-351, 1994.

WADHWA, M.; PAUL, D.; KATARIA, P. Effect of particle size of corn grains on the release of nutrients and in sacco degradability. Animal Feed Science Technology, Amsterdam, v. 72, p. 11-17, 1998. 